\title{
The NAD+/NADH Redox Couple-Insights from the Perspective of Electrochemical Energy Transformation and Biomimetic Chemistry
}

\author{
Ronald L. Reyes ${ }^{1 *}$ and Koji Tanaka ${ }^{2}$ \\ ${ }^{1}$ Organometallic Chemistry Laboratory, Department of Chemistry, Faculty of Science, Hokkaido University, \\ Sapporo 060-0810, Japan \\ ${ }^{2}$ Institute for Integrated Cell-Material Sciences, Kyoto University, Advanced Chemical Technology Center in \\ Kyoto (ACT Kyoto), Jibucho 105, Fushimiku, Kyoto 612-8374, Japan
}

\begin{abstract}
The constructions of various photochemical systems and catalysts have become a common theme in the realm of metal-catalyzed energy transformation. The biologically important redox couple $\beta$-nicotinamide adenine dinucleotide $\left(\mathrm{NAD}^{+}\right) / 1,4, \beta$-dihydronicotinamide adenine dinucleotide (NADH) provides a reversible prototype system for the conversion of electrical to chemical energy via the reversible formation of a $\mathrm{C}-\mathrm{H}$ bond centered on the nicotinamide ring representing an efficient system for numerous biological hydrogen-transfer reactions. In this short review, the first part emphasizes the need to construct operational system for the catalytic transformation of energy from viable sources due to the globally increasing demand in energy consumption. This is followed by a discussion on the redox chemistry of the NAD $/ \mathrm{NADH}$ reversible redox process centered on the nicotinamide ring as a representative chemical system enabling the efficient transformation of energy. Next, pioneering examples of $\mathrm{NAD}^{+} / \mathrm{NADH}$ mimics providing model systems that can perform non-enzymatic reactions based on the hydrogen (hydride) transfer ability of the model compounds are outlined. And lastly, several examples of ruthenium polypyridyl complexes having $\mathrm{NAD}^{+} / \mathrm{NADH}$ analogous ligands exhibiting excellent photo- and electrochemical properties similar to the $\mathrm{NAD}^{+} / \mathrm{NADH}$ redox couple are given. This is to demonstrate the importance of biomimetic chemistry in realizing novel strategies in the development of catalytic systems that can provide solutions in the alleviation or eradication of the world's energy problems.
\end{abstract}

Keywords: $N A D^{+} / N A D H$ redox couple; redox; ruthenium; biomimetic chemistry

\section{INTRODUCTION}

Metal hydrides $\left(\mathrm{LiAlH}_{4}, \mathrm{NaH}, \mathrm{NaBH}_{4}\right.$, etc. $)$ are extensively utilized as reducing agents in organic and synthetic chemistry laboratories owing to their propensity towards the catalytic reduction of many classes of substrates. This reactivity arises from the partial negative charge on the hydrogen atom present in the metal-hydrogen bond, shown in Figure 1, enabling the possibility for the metal-hydrogen bond to undergo insertion reactions in various unsaturated compounds and acting as hydride source to effect organic reduction reactions (Fulton and Perhacs, 1998; Brubach et al., 2005; Mitrasinovic, 2003). They produce stable reaction intermediates to obtain the desired product by isolation of the reduced species by either aqueous work-up or by using other suitable solvents like alcohols. One disadvantage, however, is that most of these metal hydrides are very reactive, unstable, and non-renewable. 

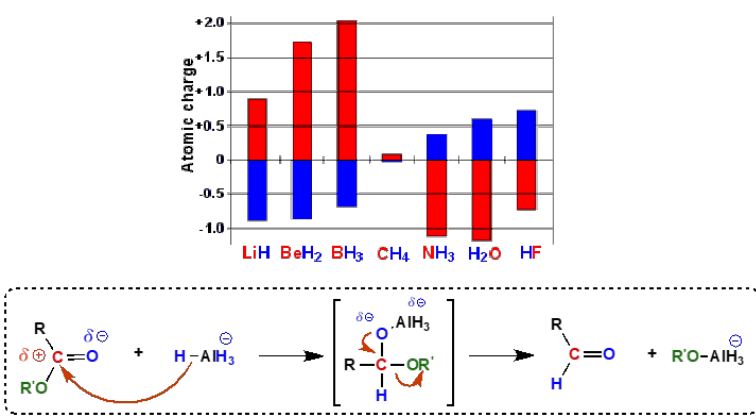

Figure 1: (Top) Charge on the Hydrogen Atoms Across Some Representative Metal Hydrides and Covalent Compounds-Charges On The H Atom are in Blue, Charges on the other Atoms are in Red. (Bottom) The Insertion Reaction Enabling Metal Hydrides to Act as Reducing Agents for Unsaturated Compounds.

In biological reactions, on the other hand, the $\mathrm{NAD}^{+} / \mathrm{NADH}$ redox couple (Figure 2) in which the oxidized form $\left(\mathrm{NAD}^{+}\right)$with a pyridinium structure is reversibly converted into the reduced form $(\mathrm{NADH})$ plays a key role in reversible hydride transfer reactions. Chemists have focused much attention on the function of NADH as an organic hydride. Considerable interest has been given in creating model compounds mimicking the activity of the $\mathrm{NAD}^{+} / \mathrm{NADH}$ redox couple (see references section for a list of preliminary work on this) from the viewpoints of using the electrochemical behavior of the $\mathrm{NAD}^{+} / \mathrm{NADH}$ redox couple in (a) modeling and studying analogous biological and biochemical phenomena (Elving, 1976; Birrell and Hirst, 2013), (b) electrochemical regeneration step in cyclic redox processes which involves chemical or energy conversion and transformation (Elving, 1976; Bresnahan and Elving, 1981; Scipioni et al., 2010) and, (c) determination of compounds which react enzymatically with $\mathrm{NAD}^{+}$or $\mathrm{NADH}$ (Dryhurst, 1977; Vidugiriene et al., 2014).

Catalytic Energy Transformation. The invention of the steam engine in the middle of the $18^{\text {th }}$ century marks the advent of increasing energy demands, utilization, and dependence. Burning tremendous amounts of fossil fuels has been common to meet the need for energy in sustaining the processes used in industrial production, manufacturing, and other practices of daily life. Alleviation of problems arising from the issue of global warming mandated the development of artificial photochemical systems. A common theme is an intensive effort towards the photochemical production of carbon monoxide (CO) and formic acid ( $\mathrm{HCOOH}$ ) from carbon dioxide $\left(\mathrm{CO}_{2}\right)$. Recent progress along these lines has resulted in advances in our understanding of the interaction of $\mathrm{CO}_{2}$ molecules with metal complexes, and the factors controlling the efficient storage of solar energy in the form of reduced carbon compounds.

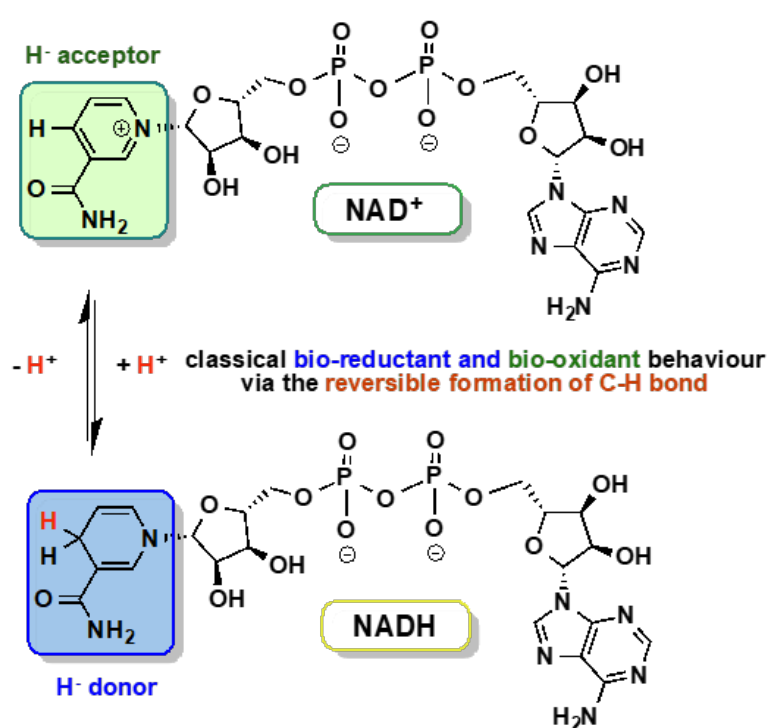

Figure 2: The Nicotinamide Adenine Dinucleotide, $N A D^{+}$, and its Reduced Form Dihydronicotinamide Adenine Dinucleotide, NADH, Redox Couple.

In 2008, Takeda and his group investigated the ability of $\left[\operatorname{Re}(\mathrm{bpy})(\mathrm{CO})_{3} \mathrm{~L}\right] \quad\left(\mathrm{L}=\mathrm{SCN}^{-}\right)$as photocatalyst for the reduction of $\mathrm{CO}_{2}$ using mechanistic studies (Takeda et al., 2008). More recently, in 2010, Khenkin and coworkers have reported a polyoxometalate substituted with RuIII, ${ }^{6} \mathrm{Q}_{5}\left[\mathrm{Ru}^{\text {III }}\left(\mathrm{H}_{2} \mathrm{O}\right) \mathrm{Si}\right.$ $\left.\mathrm{W}_{11} \mathrm{O}_{39}\right]$ in which ${ }^{6} \mathrm{Q}=\left(\mathrm{C}_{6} \mathrm{H}_{13}\right)_{4} \mathrm{~N}^{+}$, catalyzing the photoreduction of $\mathrm{CO}_{2}$ to $\mathrm{CO}$ with tertiary amines, $\mathrm{Et}_{3} \mathrm{~N}$, as reducing agent. They continue the research on the use of $\left[\operatorname{Re}^{\mathrm{I}}(\mathrm{L})(\mathrm{CO})_{3} \mathrm{X}\right](\mathrm{X}=\mathrm{Cl}, \mathrm{Br}$; and $\mathrm{L}$ = bipyridine, phenanthroline) as photocatalysts in solution for selective reduction of $\mathrm{CO}_{2}$ to $\mathrm{CO}$, and the chemistry of $\mathrm{CO}_{2}$ photoreduction using polyoxometalates (Khenkin et al., 2010). Polyoxometalates can oxidize $\mathrm{H}_{2}$ to two protons and two electrons especially in the presence of $\operatorname{Pt}(0)$.

Furthermore, polyoxometalates can combine with coordination compounds to form catalytically active metal organic-polyoxometalate hybrid complexes. Figure 3 shows the preparation of 1,10-phenanthroline decorated at the 5,6-position with a 15-crown-5 ether group, 1, so that the phenanthroline moiety can be used to prepare the needed $\operatorname{Re}(\mathrm{I})$ complex. The crown ether group is available for complexation leading to a hybrid complex $3-\operatorname{Re}^{\mathrm{I}}(\mathrm{L})(\mathrm{CO})_{3}\left(\mathrm{CH}_{3} \mathrm{CN}\right)-\mathrm{MHPW}_{12} \mathrm{O}_{40}$ where $\mathrm{L}=5,6-(15$-crown-5)-1,10-phenanthroline, $\mathrm{M}=\mathrm{H}_{3} \mathrm{O}^{+}, \mathrm{Na}^{+}$.

Photocatalytic studies using $0.5 \mu \mathrm{mol}$ of complex 3, $\mathrm{Re}^{\mathrm{I}}(\mathrm{L})(\mathrm{CO})_{3}\left(\mathrm{CH}_{3} \mathrm{CN}\right)-\mathrm{MHPW}_{12} \mathrm{O}_{40}$ in $0.5 \mathrm{~mL}$ dimethylacetamide (DMA) showed formation of $\mathrm{CO}$ while analysis of the liquid phase (GC-FID, GC-MS) did not detect the formation of additional products such as $\mathrm{CH}_{3} \mathrm{OH}, \mathrm{CH}_{2} \mathrm{O}$, or $\mathrm{CHOOH}$. This catalytic system is one of those numerous sys- 


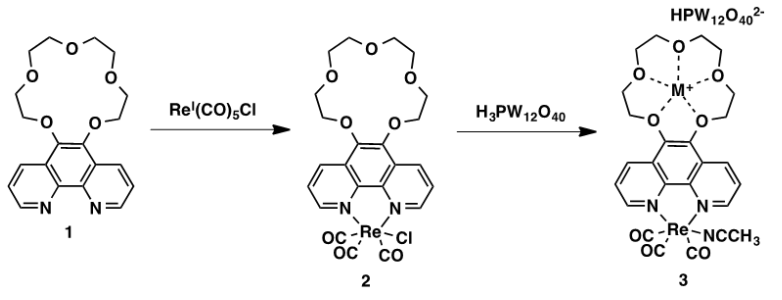

Figure 3: Preparation of the Rhenium(I) Phenanthroline-Polyoxometalate hybrid complex, 3 ( $M$ $=\mathrm{H}_{3} \mathrm{O}^{+}, \mathrm{Na}^{+}$)

tems designed towards catalytic energy transformation from chemical to electrical energy.

\section{THE NAD ${ }^{+} / \mathrm{NADH}$ REDOX COUPLE}

While the construction of various photochemical systems and catalysts have become a common theme in the realm of metal-catalyzed energy transformation, the biologically important redox couple $\beta$-nicotinamide adenine dinucleotide $\left(\mathrm{NAD}^{+}\right) / 1,4, \beta$-dihydronicotinamide adenine dinucleotide $(\mathrm{NADH})$ provides a reversible system in numerous biological hydrogen-transfer reactions. $\mathrm{NAD}^{+}$functions as a coenzyme via a proton-coupled electron transfer reaction from a substrate to form NADH. The center for the reversible redox process is the nicotinamide ring. The $\mathrm{NAD}^{+} / \mathrm{NADH}$ redox couple plays important roles as coenzymes for pyridinoproteins (dehydrogenases) in major metabolic pathways such as the electron transport chain.

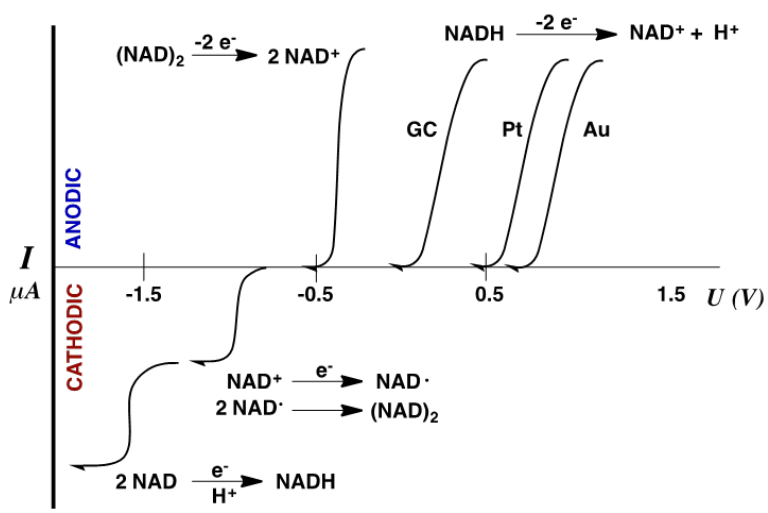

Figure 4: Composite Representation of the Voltammetric Waves for the NAD System. In this scheme, at $\mathrm{pH} 7$ and $25^{\circ} \mathrm{C}$ the formal potential for the half-reaction, $N A D^{+}+H^{+}+2 e^{-} \leftrightarrow N A D H$ is -0.557 V versus S.C.E. $G C$ is glassy carbon.

The processes involved in the electrochemical reduction of $\mathrm{NAD}^{+}$and the electrochemical oxidation of its reduced form $\mathrm{NADH}$ are summarized in Figure 4. The process starts with a one-electron reduction of $\mathrm{NAD}^{+}$to give a free radical $\mathrm{NAD}^{*}$ seen at the cathodic wave at approximately $-1 \mathrm{~V}$. The free radical NAD dimerizes to form $(\mathrm{NAD})_{2}$ followed with the subsequent one-electron reduction to form NADH at a potential of $-1.6 \mathrm{~V}$ (Elving et al., 1982; Htet and Tennyson, 2016). The dimer $(\mathrm{NAD})_{2}$ is oxidized to give $\mathrm{NAD}^{+}$at around $-0.4 \mathrm{~V}$. Furthermore, the (NAD) ${ }_{2}$ can undergo a proton-assisted disproportionation to $\mathrm{NAD}^{+}$and $\mathrm{NADH}$ (Bresnahan and Elving, 1981; Huang and $\mathrm{Liu}, 2014)$. With this behavior, the $\mathrm{NAD}^{+} / \mathrm{NADH}$ redox couple represents a reversible electrochemical prototype consisting of two successive oneelectron steps coupled with: (1) dimerization of an intermediate free radical, (2) protonationdeprotonation of the intermediate product, and (3) adsorption of reactant, intermediate species and mediation of surface species.

Cathodic Reduction of $N^{+} D^{+}$. As summarized in Figure 4, the cathodic reduction of NAD+ to NADH proceeds through a cycle involving two successive one-electron transfer reactions that are distinctly unique in potential. The first oneelectron transfer reaction involves the reduction of a cationic species. This $\mathrm{pH}$ independent Faradaic process is accompanied by events like adsorption of $\mathrm{NAD}^{+}$, free radical $\mathrm{NAD}^{\circ}$, and dimeric $(\mathrm{NAD})_{2}$. The electrochemical pattern for the NAD system is summarized in Figure 5.

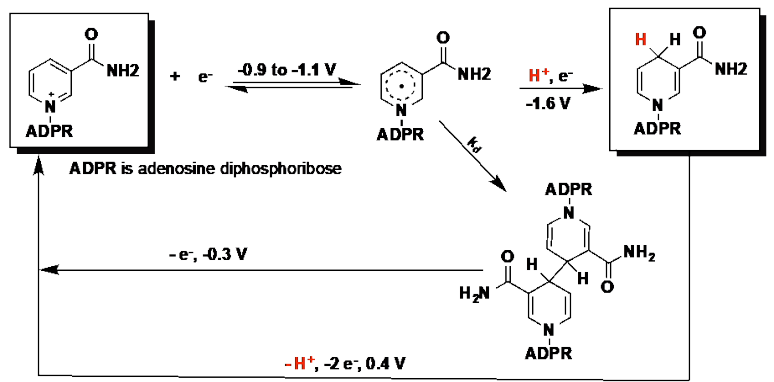

Figure 5: The Electrochemical Behavior Pattern for the NAD System. All Potentials are versus S.C.E.

The mechanistic pathway for the electrochemical reduction of $\mathrm{NAD}^{+}$to the radical $\mathrm{NAD}^{\circ}$ is dependent on several factors like the existence of competing adsorption, time-scale of the experiment, the electrode surface and its initial condition, and the background solution defined by its ionic strength and surface activity (Bresnahan and Elving, 1981; Huang and Liu, 2014). Experimentally, it has been suggested that there is a need for a protonation process before any charge transfer occurs since $\mathrm{NAD}^{\circ}$ is not reduced in aprotic media (Santhanam and Elving, 1973, Htet and Tennyson, 2016). The measured $k_{d}$ for this process, Figure 5, was $2.7 \times 10^{6}$ $\mathrm{M}^{-1} \mathrm{~s}^{-1}$ from voltammetric analysis (Bresnahan and Elving, 1981). Recently, the reduction of $\mathrm{NAD}^{+}$was studied from the viewpoint of its orientation at the solution or electrode interfaces. Studies showed that there is a perpendicular orientation of $\mathrm{NAD}^{+}$on a glassy carbon as determined from charge consumed 
on the application of a potential sweep and such is in good agreement with the sequence of chemical reactions (Santhanam and Elving, 1973; Htet and Tennyson, 2016).

Anodic Oxidation of NADH. Shown in Figure 4 are different anodic waves for the oxidation of $\mathrm{NADH}$ in various electrodes including glassy carbon (GC), platinum $(\mathrm{Pt})$, and gold $(\mathrm{Au})$. The exact nature of the electrodes affects the response and the interfacial adsorption processes involved in the electrochemical reaction. At the glassy carbon electrode, as an example, the appearance of a pre-wave is due to the weak or negligible adsorption of $\mathrm{NADH}$ and strong adsorption of $\mathrm{NAD}^{+}$:

$$
\mathrm{NADH} \stackrel{-2 e^{-}}{-\mathrm{H}^{+}} \mathrm{NAD}^{+} \longrightarrow \mathrm{NAD}_{\mathrm{ads}}^{+}
$$

The oxidation of $\mathrm{NADH}$ at any solid electrode involves an apparent single-step two- electron oxidation to enzymatically active $\mathrm{NAD}^{+}$as shown below:

$$
\mathrm{NADH} \longrightarrow \mathrm{NAD}^{+}+\mathrm{H}^{+}+2 e^{-}
$$

This explains why NADH showed a single diffusioncontrolled cyclic voltammetric anodic peak and any reversal in the scan generated a cathodic peak due to the $\mathrm{NAD}^{+}$at a more negative potential. Summarized in Figure 6 is the reaction pathway for the electrochemical oxidation of NADH. The process involves equilibrium reactions that lead to the establishment of a reaction scheme in the electrochemical oxidation of NADH via an ECE (Electron transfer, Chemical reaction, Electron transfer) mechanism (Bresnahan and Elving, 1981; Huang and Liu, 2014; Ma et al., 2015). The summary of values calculated for the equilibrium constants were summarized on the works of Bresnahan and Elving. The temperature dependence of $k$ at the GC electrode at $\mathrm{pH} 7.1$ is a confirmation of the presence of a chemical limiting step. The magnitudes of $\mathrm{k}$ correlate with the extent of electrode coverage by the absorbed $\mathrm{NAD}^{+}$. This supports the idea that $\mathrm{NAD}^{+}$acts as a mediator with respect to electron and proton transfer during $\mathrm{NADH}$ oxidation.

Both reduced and oxidized forms of $\beta$-nicotinamide adenine dinucleotide (NADH and $\mathrm{NAD}^{+}$, respectively) are important coenzymes for a large number of dehydrogenase enzymes, catalyzing the removal of a hydrogen from a substrate and the consequential transfer of the hydrogen to an acceptor in a redox active system, and as indespensible components of biomarkers (White, 1982; Ma et al., 2015). Furthermore, given its crucial role in the fields of analytical electrochemistry (Radoi and Compagnone, 2009), bio-electrocatalysis
(Limoges et al., 2006; Bardea et al., 1997; Li et al., 2012), and the emerging trends in biofuel cells, the electrochemical evaluation and investigation for the formal potential and redox chemistry of the $\mathrm{NAD}^{+} /$ $\mathrm{NADH}$ redox couple has attracted considerable attention and interest.
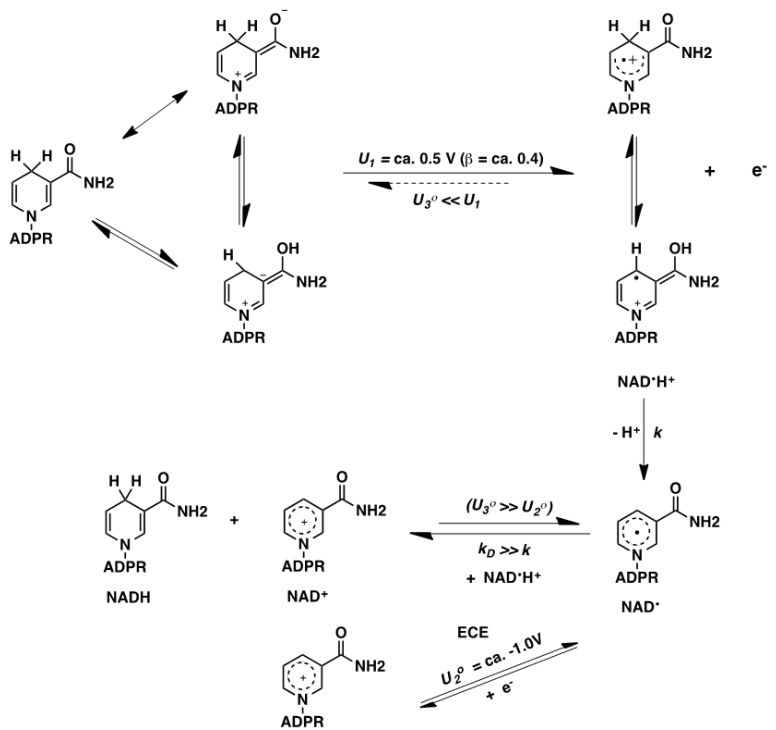

Figure 6: A Summary of the Reaction Pathway for the Electrochemical Oxidation of NADH. $U_{1}$, is the oxidation potential of $\mathrm{NADH}$ to $\mathrm{NADH}^{+} ; \mathrm{U}_{2}{ }^{0}$ is the reversible potential for the $N A D^{+} / N A D^{\circ}$ couple; $U_{3}{ }^{\circ}$ is the reversible potential for the $N A D H^{+}$couple; $k$ is the deprotonation rate constant; $k_{D}$, is a disproportionation rate constant. All potentials are versus S.C.E.

\section{PIONEERING EXAMPLES OF NAD ${ }^{+}$ NADH MIMICS}

Nature provides numerous enzymatic redox transformations that happen rapidly without any realized difficulty in addition to the high stereoselectivity exhibited by these enzymemediated reactions. Thus, nature is a source of inspiration towards the development of biomimetic stereoselective redox reagents that can play crucial roles in catalysis, industrial and agrochemistry, as well as in organic synthesis laboratories. $\mathrm{NADH}$ mimics, for example, have been extensively studied in biomimetic transformations. Mimics without the actual use of biological enzymes and supramolecular structures such as organic compounds that can perform the biochemical function of $\mathrm{NADH}$ and related molecules are highly desirable. For example, some NADH mimics that can perform the stereoselective reduction of benzoylformates to the corresponding mandelates show this reactivity clearly. Chiral dihydronicotinoyl derivatives as $\mathrm{NADH}$ mimics can interact with substrates such as benzoylformates in many possible conformations given by the two enantiotopic faces of the $\alpha$-ketoester and the two diastereotopic faces 
of the dihydropyridine ring, giving four possible approaches as outlined in Figure 7 . This reactivity has been studied in the late 1980's and early 90's and provides a pioneering example to the synthetic utility of simple NADH mimics.

High stereoselectivity in these biomimetic systems is achievable by realizing possible ways to provide restrictions similar to the enzymatic methods driven by conformational changes within the active site in biologically controlled reaction. With this requirement model systems can be designed with the preferential reactivity while substrate approach to the dihydropyridine moiety is constrained with a fixed orientation. For example, in the stereoselective reduction of benzoylformates to the corresponding mandelates, the ester portion of the substrate can approach directly over the $-\mathrm{R}^{*}$ group at the dihydropyridine ring that incorporates sterically demanding or chiral side chains. However, the limitations in the approach pathways (Figure 7, A and B) does not inevitably result in the selective formation of the $(R)$ or $(S)$-mandelates (Burgess et al., 1991). An approach of the si-face of the substrate to pro- $(R)$ hydrogen in an orientation such as the ester is lying over the $\mathrm{R}^{*}$ substituent delivers $(R)$-mandelate as the product whereas approach of the re-face gives $(S)$-mandelate, the same is true for pathways $\mathrm{C}$ and $\mathrm{D}$ shown in Figure 7.

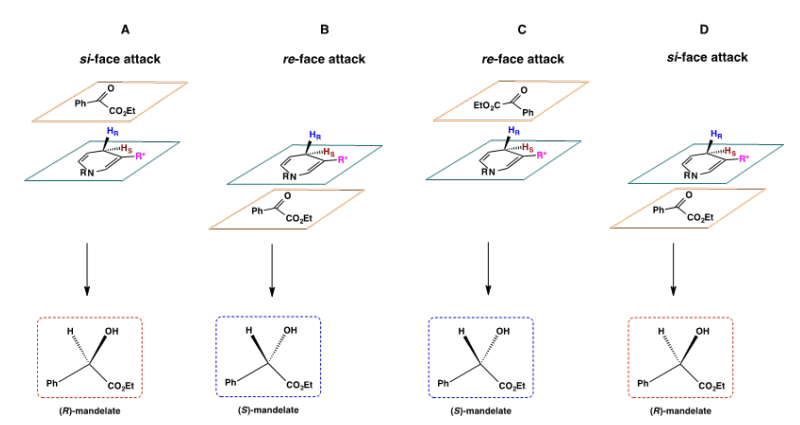

Figure 7: Four Possible Approach Pathways to the Interaction between the Two Enantiotopic Faces of the a-Ketoester and the Two Diastereotopic Faces of the Dihydropyridine Ring. $R^{*}$ at the C-4 position incorporates sterically demanding or chiral side chains.

Ohnishi and coworkers (Ohnishi et al., 1975) reported the first $\mathrm{NADH}$ model compound capable of stereoselective reduction of a prochiral substrate having a 1,4-dihydropyridine derivative possessing a chiral carboxamide at $\mathrm{C}-3$. This pioneering work also proved the essentiality for the presence of divalent metal ion, which in most instances, is the divalent magnesium added to the reaction mixture in the form of magnesium salts such as magnesium perchlorate. Since Ohnishi and coworkers reported this reduction reaction by a NADH model system, a large number of such biomimetic systems have been developed (for a list of works on benzoylformate reduction by $\mathrm{NADH}$ mimics see reference section). Table 1 summarizes some of these model NADH mimics.

Zhao and coworkers reported a more recent development to this transformation in 2007. In their $\mathrm{NADH}$ mimic four chiral carbon centers were introduced using $(1 R, 2 R)$-diaminocyclohexane, Figure 8. This model compound has a $\mathrm{C}_{2}$-symmetric structure that can take advantage of an efficient bi-directional synthetic preparation methodology (Zhao et al., 2007). Thus, this $\mathrm{C}_{2}$-symmetric $\mathrm{NADH}$ mimics were able to enantioselectively reduce the pyruvate mimic methyl benzoylformate in acetonitrile at room temperature giving $(R)$ mandelate as the product.

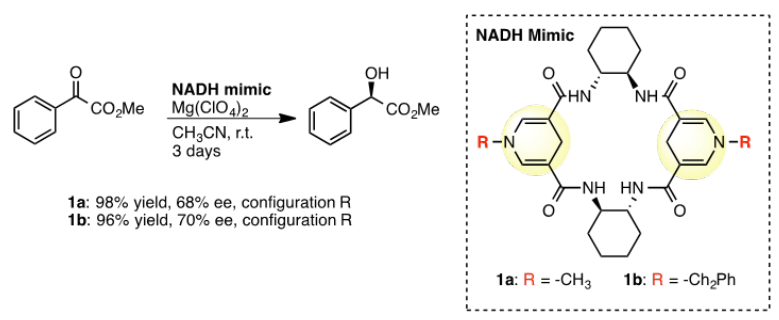

Figure 8. Enantioselective Reduction of Benzoylformate Using a $C_{2}$-symmetric NADH Mimics.

\section{COMPLEXES WITH NAD+/NADH ANALOGOUS LIGANDS}

Scientists have focused much attention to $\mathrm{NADH}$ as an organic hydride donor. Numerous kinetic studies of hydride transfer, reduction of carbonyl compounds in an asymmetric fashion, protoncoupled electron transfer with NADH and its model compounds have been investigated (see reference section for a list of works on this topic). However, all the reactions involving $\mathrm{NAD}^{+} / \mathrm{NADH}$ model systems present stoichiometric reactions. One example of an electrochemical system behaving in a similar way as the $\mathrm{NAD}^{+} / \mathrm{NADH}$ redox couple is a model compound reported by our research group (Tomon et al., 2005; Nakajima and Tanaka, 1995), Figure 9. With the goal towards the polypyridyl ruthenium carbonyl complex mediated electro- and photochemical reduction of carbon dioxide, also relying on the ligand based redox reaction as the source of electrons required for the reduction, our group examined the possibility of metallacyclization of $\mathrm{Ru}($ napy $\left.-\kappa \mathrm{N})(\mathrm{CO})(\mathrm{bpy})_{2}\right]\left(\mathrm{PF}_{6}\right)_{2}$, where napy and bpy are the 1,8-naphthyridine and bipyridine moieties respectively. Such process can be driven by the ligand based redox reaction on the naphthyridine ring resulting to the enhancement of the nucleophilicity of the non-bonded nitrogen atom triggering an intramolecular attack at the $\alpha$-carbon of a neighboring ligand in generating a metallacycle. 


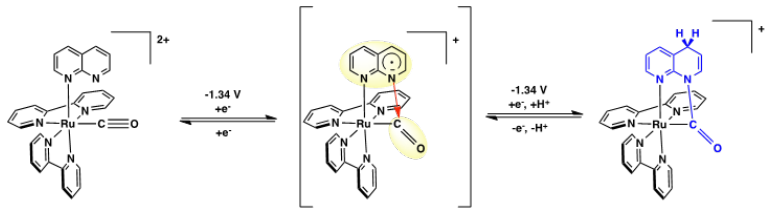

Figure 9: The Electrochemical Reduction of cis$\left[R u(n a p y-x N)(C O)(b p y)_{2}\right]\left(P F_{6}\right)_{2}$-an $N A D^{+} / N A D H$ redox couple model.

Table 1. Pioneering Examples of Asymmetric Reduction of Methyl Benzoylformate by $\mathrm{NADH}$ Mimics.

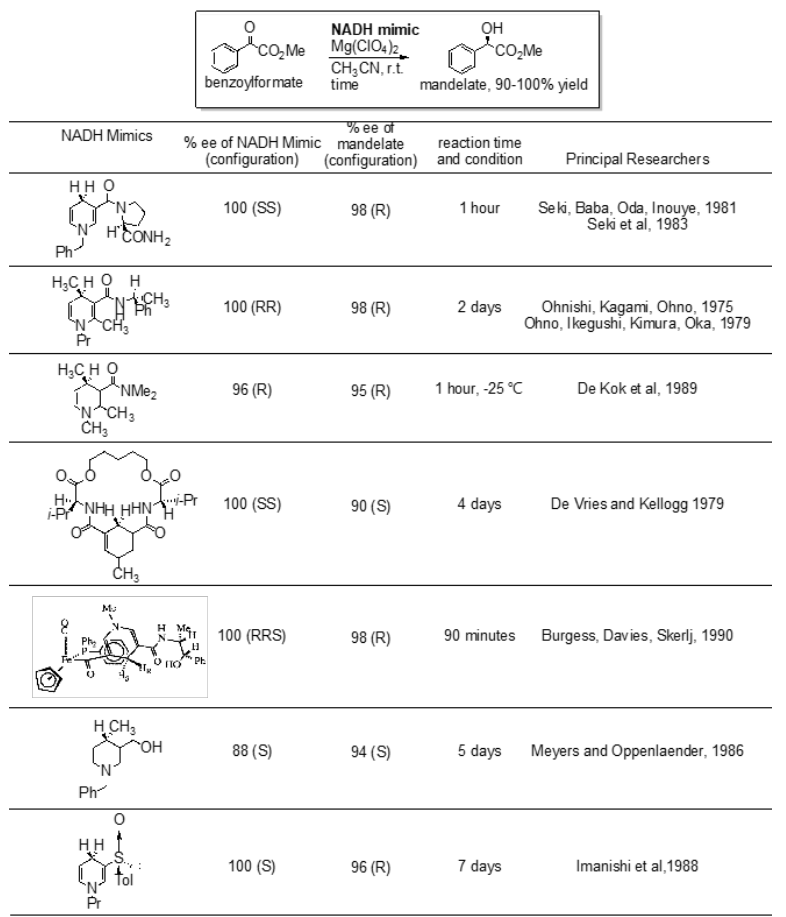

The electrochemical reduction of $c i s-[\mathrm{Ru}($ napy $-\varkappa \mathrm{N})$ $\left.(\mathrm{CO})(\mathrm{bpy})_{2}\right]\left(\mathrm{PF}_{6}\right)_{2}$ (Figure 9) at $-1.34 \mathrm{~V}$ (versus the ferrocene/ferrocenium, $\mathrm{Fc} / \mathrm{Fc}^{+}$, couple) resulted in the formation of a bond between the noncoordinating nitrogen atom in the naphthyridine ring and the carbonyl carbon followed by the subsequent hydrogenation of the naphthyridine ring. The reduced complex upon re-oxidation at $0.06 \mathrm{~V}$ fully regenerated the original complex. This exhibited behavior is in good agreement with the $\mathrm{NAD}^{+} / \mathrm{NADH}$ redox couple.

The reversible formation of $\mathrm{C}-\mathrm{H}$ bond in the model system showed the versatile properties of the redox couple in using the $\mathrm{C}-\mathrm{H}$ bond as a way to store energy. Other systems have also been shown to have the ability to store chemical energy and transform this to electrical energy. Tri-nuclear $\left[\left\{(\text { bpy })_{2} \mathrm{Ru}(\mathrm{dpb})\right\}_{2} \mathrm{IrCl}_{2}\right]^{5+}$ (bpy = 2,2'-bipyridine, $\mathrm{dpb}=2,3$-bis(2-pyridyl)benzoquinoxaline) reported by Molnar and coworkers in 1994, and the tetranuclear $\left[\left\{(\text { bpy })_{2} \mathrm{Ru}(\mathrm{dmbbbpy})\right\}_{3} \mathrm{Ru}\right]^{8+}$ (dmbbbpy $=2,2^{\prime}$-bis $(\mathrm{N}$-methylbenzimidazole-2-yl)-4,4'-bipyri- dine) reported by Ali and coworkers in 1998, have been shown to have the ability in storing more than one photoexcited electron in the $\pi^{*}$ orbitals of the ligands using a sacrificial donor of electron. Furthermore, dinuclear [(phen $)_{2} \mathrm{Ru}($ tatpq $)$ $\left.\mathrm{Ru}(\text { phen })_{2}\right]^{4+}$ (phen $=1,10$-phenanthroline, tatpq $=$ 9,11,20,22-tetraazatetrapyrido[3,2-a:2'3'-c:3",2"1:2"',3'"-n] pentacene-10,21-quinone) (Wouters et al., 2006) has been shown to undergo a photoinduced two- and four-electron reduction of the bridging ligand in the presence of sacrificial electron donor such as triethylamine (TEA) or triethanolamine (TEOA).

Inspired by the possibility of constructing a system that has an ability to mimic the $\mathrm{NAD}^{+} /$ $\mathrm{NADH}$ as an organic hydride donor, rutheniumpolypyridyl complexes have become a representation of NADH mimics. Recently, we have also reported the mononuclear ruthenium complex $\left[\mathrm{Ru}(\mathrm{bpy})_{2}(\mathrm{pbn})\right]\left(\mathrm{PF}_{6}\right)_{2}$ where bpy is bipyridine and pbn is 2-(2-pyridyl)benzo[b]-1,5-naphthyridine) (Koizumi and Tanaka, 2005) has shown to undergo electrochemical reduction under aqueous condition that induced the formation of a hydrogenated product $\left[\mathrm{Ru}(\mathrm{bpy})_{2}\left(\mathrm{pbnH}_{2}\right)\right]\left(\mathrm{PF}_{6}\right)_{2}\left(\mathrm{pbnH}_{2}=5,10\right.$-dihydro2-(2-pyridyl)benzo[b]-1,5-naphthyridine). Also, this complex has been shown to be smoothly reduced to the hydrogenated product by photo-induced twoelectron reduction of $\mathrm{pbn}$ under irradiation with visible light in the presence of a sacrificial reagent TEA or TEOA, shown in Figure 10.
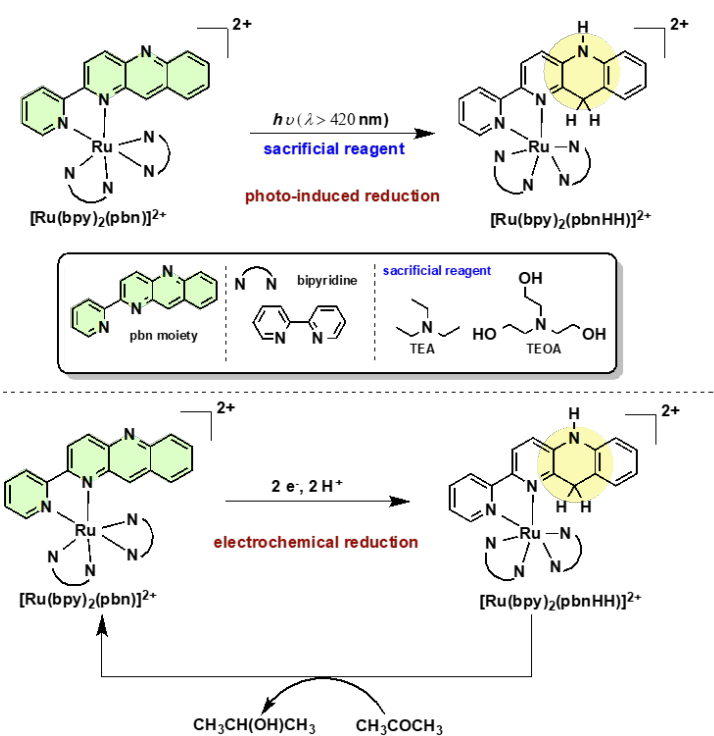

Figure 10. The Photo-induced Ligand Based Reduction of $\left[R u(b p y)_{2}(p b n)\right]\left(P F_{6}\right)_{2}$ (top) and the Electrochemical Reduction of $\left[R u(b p y)_{2}(p b n)\right]\left(P F_{6}\right)_{2}$ with the Concomitant Reduction of Acetone to Isopropanol. 
Electrocatalytically, it has been shown that $\left[\mathrm{Ru}(\mathrm{bpy})_{2}(\mathrm{pbn})\right]_{\left(\mathrm{PF}_{6}\right)_{2}}$ was able to catalyzed the reduction of acetone to isopropanol with the hydrogenated form of the complex, $\left[\mathrm{Ru}(\mathrm{bpy})_{2}\left(\mathrm{pbnH}_{2}\right)\right]\left(\mathrm{PF}_{6}\right)_{2}$, as the key intermediate. By using pulse and steady-state radiolysis studies the mechanism of hydride donor generation for this complex has been extensively studied. Shown in Figure 11 is the mechanism for the formation of the hydrogenated form of the complex and the generation of the hydride donor (Polyansky et al., 2008).

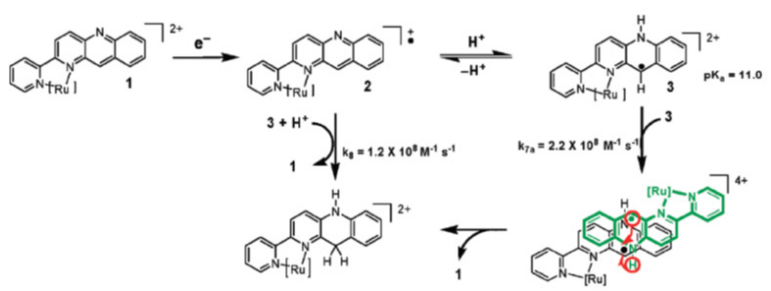

Figure 11: The Mechanistic Pathway for the Electrochemical Reduction of $\left[R u(b p y)_{2}(p b n)\right]\left(P F_{6}\right)_{2}$. Here water may be a source of $H^{+}$at high $p H$.

The electrochemical reduction of $\left[\mathrm{Ru}(\mathrm{bpy})_{2}(\mathrm{pbn})\right]$ $\left(\mathrm{PF}_{6}\right)_{2}$ involves the photo-excitation of the complex followed by the reductive quenching of the photoexcited form of the complex by a sacrificial electron donor that produces $\left[\mathrm{Ru}(\mathrm{bpy})_{2}\left(\mathrm{pbn}^{-}\right)\right]^{+}$. This species is then protonated to the noncoordinating nitrogen atom of the pbn generating a mono-hydrogenated species $\left[\mathrm{Ru}(\mathrm{bpy})_{2}\left(\mathrm{pbnH}^{\circ}\right)\right]^{2+}$ which rapidly undergoes dimerization through a $\pi-\pi$ adduct formation between the two neutral $\mathrm{pbnH}^{\circ}$ of $\left[\mathrm{Ru}(\mathrm{bpy})_{2}\left(\mathrm{pbnH} \mathrm{H}^{*}\right)\right]^{2+}$. Finally, an intramolecular electron and proton transfer from one $\mathrm{pbnH}^{\circ}$ to another in $\left[\left\{\mathrm{Ru}(\mathrm{bpy})_{2}\left(\mathrm{pbnH}^{\circ}\right)\right\}_{2}\right]^{4+}$ allows a disproportionation reaction giving a 1:1 mixture of $\left[\mathrm{Ru}(\mathrm{bpy})_{2}\left(\mathrm{pbnH}_{2}\right)\right]^{2+}$ which is the two-electron reduced form and $\left[\mathrm{Ru}(\mathrm{bpy})_{2}(\mathrm{pbn})\right]^{2+}$ which is the original complex.

More recently, in 2015, further utilization of the $\mathrm{NADH}$ model ligand $\left[\mathrm{Ru}(\mathrm{bpy})_{2}(\mathrm{pbnHH})\right]\left(\mathrm{PF}_{6}\right)_{2}$ in converting carbon dioxide to formate has been reported (Ohtsu et al., 2015). The rate of organic hydride transfer reaction mediated by the NADH model complex has been succesfully controlled by the tuning of basicity of the bases. Thus, the difference in the basicity of $\mathrm{MeCOO}-, \mathrm{PhCOO}-$, and $\mathrm{CF}_{3} \mathrm{COO}-$ has been shown to control the rate of the organic hydride reduction activity of the complex towards carbon dioxide reduction to formate, $\mathrm{HCO}_{2}^{-}$. This accelerating and decelerating effect is driven by the association of the corresponding bases to the free $\mathrm{N}-\mathrm{H}$ moiety found on the NADH model ligand, $\left[\mathrm{Ru}(\mathrm{bpy})_{2}(\mathrm{pbnHH})\right]\left(\mathrm{PF}_{6}\right)_{2}$.
Another notable ruthenium complex displaying an interesting electro- and photochemical redox behavior is a mononuclear complex [Ru(bbnp) (terpy) $]\left(\mathrm{PF}_{6}\right)_{2}$ where terpy is $2,2^{\prime}: 6^{\prime}, 2^{\prime \prime}$-terpyridine and bbnp is 2,6-bis(benzo[b]-1,5-naphthyridin6-yl)-4-tert-butylpyridine (Tannai et al., 2007). The corresponding two- and four-electron reduced complexes of this ruthenium compound are $\left[\mathrm{Ru}\left(\mathrm{bbnpH}_{2}\right)(\right.$ terpy $\left.)\right]\left(\mathrm{PF}_{6}\right)_{2}$ and $\left[\mathrm{Ru}\left(\mathrm{bbnpH}_{4}\right)\right.$ (terpy) $]\left(\mathrm{PF}_{6}\right)_{2}$ respectively.

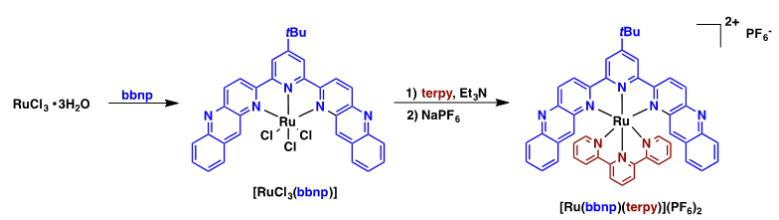

Figure 12. Synthesis of $[R u(b b n p)(t e r p y)]\left(P F_{6}\right)_{2}$.

The synthesis of $[\mathrm{Ru}(\mathrm{bbnp})($ terpy $)]\left(\mathrm{PF}_{6}\right)_{2}$ complex, shown in Figure 12, involved a two-step reaction starting with the coordination of bbnp followed by the coordination of the other ligand terpy. The cyclic voltammetric analysis of this complex showed four reversible redox couples. The redox reactions at $E_{1 / 2}=$ $+1.48 \mathrm{~V}$ and $-1.42 \mathrm{~V}$ (all versus S.C.E.) is attributed to the $\mathrm{Ru}^{\mathrm{II}} / \mathrm{Ru}^{\mathrm{III}}$ couple and the ligand localized redox process (terpy ${ }^{-} /$terpy) couple. The other two remaining redox couples observed at $E_{1 / 2}=-0.68 \mathrm{~V}$ and $-0.88 \mathrm{~V}$ resulted from two successive ligandlocalized couples: (bnp, bnp)/(bnp ${ }^{-}$, bnp) and (bnp ${ }^{-}$ ; bnp $) /\left(\right.$ bnp $^{-}$, bnp $\left.{ }^{-}\right)$. Moreover, the electrochemical oxidation of the four-electron reduced complex fully regenerated the original dehydrogenated complex, Figure 13.

The electrochemical behavior of these inorganic complexes is in good agreement with the $\mathrm{NAD}^{+} /$ $\mathrm{NADH}$ electrochemistry. This leads to the development of renewable catalysts that can be used for the reduction of organic and inorganic substrates. Renewable catalysts for the reduction of alkyl halides, olefins, and ketones in addition to various photo-induced electron transfer and thermal reactions can be realized. Furthermore, this has led to the possibility of using $\mathrm{CO}_{2}$ as a substrate and converts this greenhouse gas to reduced organic compounds like formic acid and methanol that can generate fuel as a renewable and sustainable resource for a clean and green energy-dependent society.

More recently, Kobayashi and coworkers in 2016 reported the photochemical properties of an $\mathrm{NAD}^{+} / \mathrm{NADH}$-functionalized ruthenium polypyridyl complex having an $\mathrm{NAD}^{+} / \mathrm{NADH}$ analogous functionality at the $f$-position of the 1,10-phenanthroline moiety, Figure 14. The NAD form as well as the NADH form showed improved and significant light emission properties as compared 
to those ruthenium polypyridyl complexes mentioned in this review ( $\mathrm{Ru}-\mathrm{pbn}$ complexes). The bpp(benzo[b]pyrido[3,2-f][1,7]-phenanthroline) moiety has been shown to store photoreducing energy via a structural conversion consistent to the $\mathrm{NAD}^{+} / \mathrm{NADH}$ redox couple.

a.
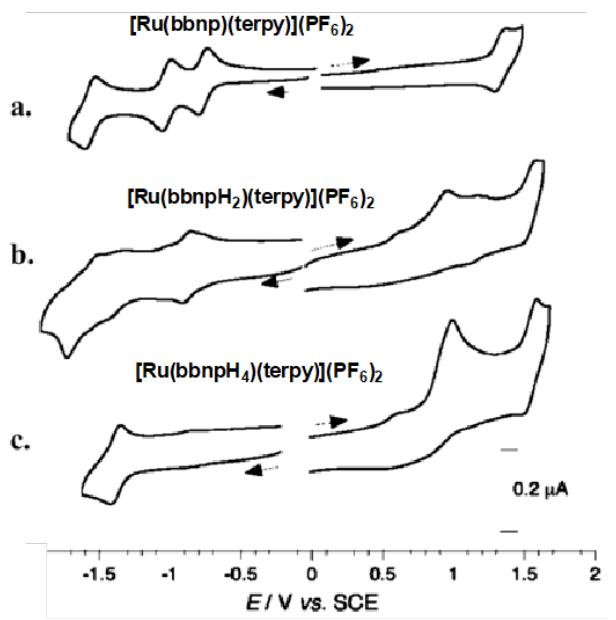

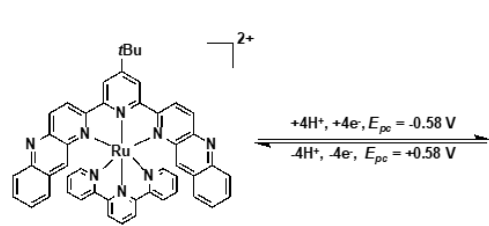

[Ru(bbnp)(terpy)] $\left(\mathrm{PF}_{6}\right)_{2}$

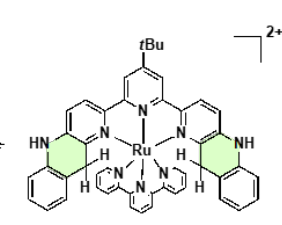

$\left[\mathrm{Ru}\left(\mathrm{bbnpH}_{4}\right)(\right.$ terpy $\left.)\right]\left(\mathrm{PF}_{6}\right)_{2}$
Figure 13. The Electrochemical Reduction and Oxidation of $[R u(b b n p)($ terpy $)]\left(P_{6}\right)_{2}$ and Its Hydrogenated Complexes in $\mathrm{CH}_{3} \mathrm{CN}$ Solution. Scan Directions are Denoted by the Arrows.

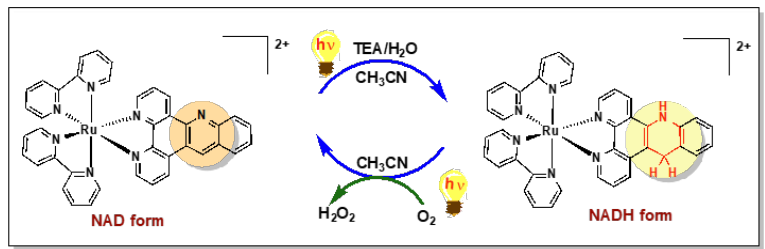

Figure 14. Molecular Structures of $\left[R u(b p p)(b p y)_{2}\right]^{2+}$ $(N A D$ Form $)$ and $\left[R u(b p p H H)(b p y)_{2}\right]^{2+}(N A D H$ Form).

Electrochemically, the cyclic voltammogram of $\left[\mathrm{Ru}(\mathrm{bpp})(\mathrm{bpy})_{2}\right]^{2+}$ exhibited four reversible redox couples at $1.23,-1.28,-1.43$, and $-1.63 \mathrm{~V}$ vs SCE in DMF, Figure 15. The redox couple observed at $1.23 \mathrm{~V}$ can be attributed to the $\mathrm{Ru}(\mathrm{II}) / \mathrm{Ru}(\mathrm{III})$ metal-centered redox process. When acetic acid was added as a proton source the reversibility of the redox couple present at $-1.28 \mathrm{~V}$ was lost with a generation of a new anodic peak at $0.8 \mathrm{~V}$. The remaining two couples occurring at the more negative potential that were unchanged before and after the acid addition can be attributed to the redox processes at the two-bipyridine ligands. The irreversible +0.8 $\mathrm{V}$ anodic wave not appearing in the initial anodic potential sweep emerged after the potential sweep was returned at $-1.4 \mathrm{~V}$. This demonstrated a large separation between the cathodic and anodic peak potentials of the bpp localized redox process arising from the protonation of the non-coordinated nitrogen atom in the bpp moiety. Furthermore, the NADH form $\left[\mathrm{Ru}(\mathrm{bppHH})(\mathrm{bpy})_{2}\right]^{2+}$, has been demonstrated to reduce molecular oxygen while regenerating the origal complex $\left[\mathrm{Ru}(\mathrm{bpp})(\mathrm{bpy})_{2}\right]^{2+}$ under photoirradiation. By monitoring the NMR spectrum of $\left[\mathrm{Ru}(\mathrm{bppHH})(\mathrm{bpy})_{2}\right]^{2+}$ solution, its selective oxidation to $\left[\mathrm{Ru}(\mathrm{bpp})(\mathrm{bpy})_{2}\right]^{2+}$ without any trace of degradation products was clearly demonstrated. The production of hydrogen peroxide was also confirmed. Finally, the reasonable mechanism for this transformation was proposed, Figure 16.

The results demonstrated in this ruthenium polypyridyl chemistry bearing a site analogous to the $\mathrm{NAD}^{+} / \mathrm{NADH}$ redox couple presents a new strategy for the development of novel platforms and molecular design motiffs for realizing renewable hydride catalysts towards the grand goal of efficient energy conversion between electrical and chemical energy in creating an energy-secured and sustainable society.

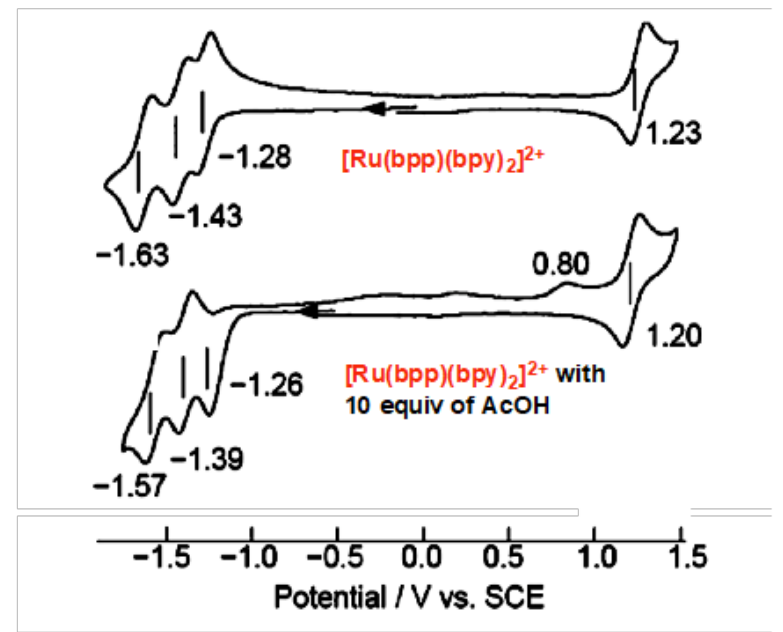

Figure 15: Cyclic Voltammograms of $\left[R u(b p p)(b p y)_{2}\right]^{2+}$ in the Absence and Presence of 10 equiv of $\mathrm{AcOH}$ in $D M F$ at $d V / d t=0.1 \mathrm{~V} / \mathrm{s}$.

\section{INSIGHTS AND PERSPECTIVES}

The goal to provide a sustainable society for the next generation has inspired numerous researches in many fields of the sciences. Among these fields, catalysis using transition-metal chemistry has fluorished as a useful and attractive strategy in dealing with energy problems that our society is facing now. As with many other systems, nature proves to be the best source of motivation and inspiration. Biomimetic chemistry has advanced greatly because of the potential it offers 


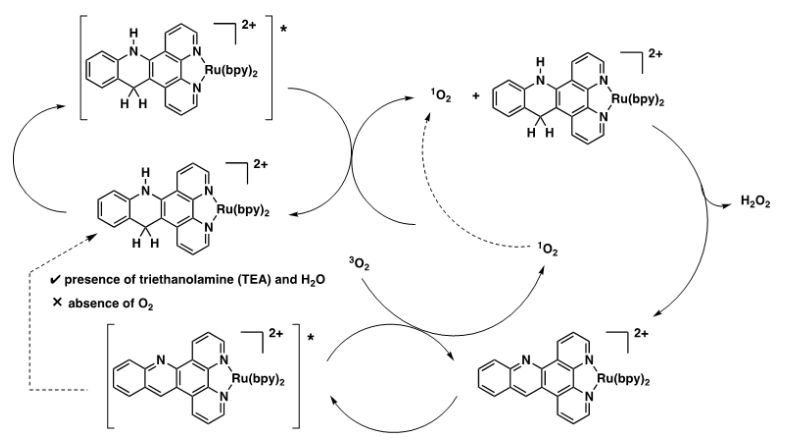

Figure 16: A Schematic Representation of the Most Resonable Reaction Mechanism for the Transformation: $\left[\mathrm{Ru}(b p p H H)(b p y)_{2}\right]^{2+}+\mathrm{O}_{2} \rightarrow\left[\mathrm{Ru}(b p p)(b p y)_{2}\right]^{2+}+$ $\mathrm{H}_{2} \mathrm{O}_{2}$.

in delivering solutions to several problems both of the society and difficulties normally encountered in many reactions in the laboratories and in the industry. For example, efficient transformation of electrical to chemical energy has been shown by the $\mathrm{NAD}^{+} / \mathrm{NADH}$ redox couple via the formation of a chemical bond without any difficulty. By looking into the behaviour of this classical system, researches to mimic its biochemical activity have span over the last few decades. Indeed, nature can provide us with solutions. We simply need to look at the intricacies of nature's structure and function. In the future, more technological advancement should bring us to encountering nature's wonders and how we can harvest such wonders to provide real and concrete solutions especially in the world's increasing energy demand and alleviation of problems arising from global warming.

\section{CONCLUSION}

Redox reactions remain the most viable source in providing the chemical motive force essential for all forms of life. The biologically important redox couple, $\mathrm{NAD}^{+} / \mathrm{NADH}$ provides a reversible prototype system for the conversion of electrical to chemical energy via the reversible formation of a $\mathrm{C}-\mathrm{H}$ bond centered on the nicotinamide ring. The $\mathrm{NAD}^{+} / \mathrm{NADH}$ redox couple plays important roles as coenzymes for pyridinoproteins (dehydrogenases) in major metabolic pathways such as the electron transport chain. Biomimetic chemistry of the $\mathrm{NAD}^{+} / \mathrm{NADH}$ redox couple has provided numerous examples of non-enzymatic reactions mediated by the reactivity analogous to the electrochemical process involved in the redox reactions in the $\mathrm{NAD}^{+} / \mathrm{NADH}$ redox couple. Moreover, biomimetic ruthenium polypyridyl chemistry has provided excellent model systems that demonstrated functionality similar to the $\mathrm{NAD}^{+} / \mathrm{NADH}$ redox couple. This has resulted to the preparation of ligand systems and transition metal complexes that can harness the hydride donating ability of $\mathrm{NADH}$ for catalytic applications such as reduction reactions of $\alpha$-keto esters, alcohols and other organic substrates. Moreover, the activation of molecular oxygen via the reduction to hydrogen peroxide was also demonstrated. This should provide novel strategies towards the development of catalytic systems that can give advantageous results in the alleviation or eradication of our energy problems.

\section{REFERENCES}

Ali MM, Sato H, Haga M-A, Tanaka K, Yoshimura A, Ohno T. Two-Electron Reduction of $[\{(\mathrm{bpy}) 2 \mathrm{Ru}(\mathrm{dmbbbpy})\} 3 \mathrm{Ru}] 8+$ from (BNA) 2 via Photoinduced Electron Transfer [dmbbbpy $=\quad 2,2^{\prime}-\mathrm{Bis}(\mathrm{N}$-methylbenzimidazole-2-yl $)-4,4^{\prime}-$ bipyridine]. Inorg Chem. 1998;37(24).

Bardea A, Katz E, Bückmann AF, Willner I. NAD+Dependent Enzyme Electrodes: Electrical Contact of Cofactor-Dependent Enzymes and Electrodes. J Am Chem Soc. 1997 Oct;119(39):9114-9.

Birrell JA, Hirst J. Investigation of NADH Binding, Hydride Transfer, and NAD+ Dissociation during NADH Oxidation by Mitochondrial Complex I Using Modified Nicotinamide Nucleotides. Biochemistry. 2013 Jun 11;52(23):4048-55.

Bresnahan W, Elving P. Spectrophotometric investigation of products formed following the initial one-electron electrochemical reduction of nicotinamide adenine dinucleotide (NAD+). Biochim Biophys Acta - Gen Subj. 1981 Dec 4;678(2):151-6.

Bresnahan WT, Elving PJ. The role of adsorption in the initial one-electron electrochemical reduction of nicotinamide adenine dinucleotide (NAD+). J Am Chem Soc. 1981 May;103(9):2379-86.

Brubach J-B, Mermet A, Filabozzi A, Gerschel A, Roy P. Signatures of the hydrogen bonding in the infrared bands of water. J Chem Phys. 2005 May 8;122(18):184509.

Burgess VA, Davies SG, Skerlj RT. NADH mimics for the stereoselective reduction of benzoylformates to the corresponding mandelates. Tetrahedron: Asymmetry. 1991 Jan;2(5):299-328.

Burgess VA, Davies SG, Skerlj RT. Chiral organometallic NADH mimics: stereoselective reduction of ethyl benzoylformate utilising the homochiral auxiliary $[(\eta 5-\mathrm{C} 5 \mathrm{H} 5) \mathrm{Fe}(\mathrm{CO})(\mathrm{PPh} 3)]$ at $\mathrm{C}-3$ and a chiral $\beta$-hydroxy-carboxamide derived from valinol at C-5. J Chem Soc, Chem Commun. 1990;(24):1759-62. 
De Kok PMT, Bastiaansen LAM, Van Lier PM, Vekemans JAJM, Buck HM. Highly reactive and stereoselective (R)- and (S)-3(N,N-dimethylcarbamoyl)-1,2,4-trimethyl-1,4dihydropyridines for NADH-NAD+ mimicry. J Org Chem. 1989 Mar;54(6):1313-20.

De Kok PMT, Bastiaansen LAM, Van Lier PM, Vekemans JAJM, Buck HM. Highly reactive and stereoselective (R)- and (S)-3(N,N-dimethylcarbamoyl)-1,2,4-trimethyl-1,4dihydropyridines for NADH-NAD+ mimicry. J Org Chem. 1989 Mar;54(6):1313-20.

De VJG, Kellogg RM. Asymmetric reductions with a chiral 1,4-dihydropyridine crown ether. J Am Chem Soc. 1979;101(10):2759-61.

Dryhurst G. Electrochemistry of Biological Molecules. New York: Academic Press; 1977.

Elving PJ. No Title. In: Milazzo G, editor. Topics in Bioelectrochemistry and Bioenergetics. New York: Wiley-Interscience; 1976. p. 278.

Elving PJ, Bresnahan WT, Moiroux J, Samec Z. $\mathrm{NAD} / \mathrm{NADH}$ as a model redox system: Mechanism, mediation, modification by the environment. J Electroanal Chem Interfacial Electrochem. 1982 Jul;141(3):365-78.

Fulton RL, Perhacs P. Sharing Analysis of the Behavior of Electrons in Some Simple Molecules. J Phys Chem A. 1998 Nov;102(45):8988-9000.

Htet Y, Tennyson AG. NAD+ as a Hydride Donor and Reductant. J Am Chem Soc. 2016 Dec 14;138(49):15833-6.

Huang J, Antonietti M, Liu J. Bio-inspired carbon nitride mesoporous spheres for artificial photosynthesis: photocatalytic cofactor regeneration for sustainable enzymatic synthesis. J Mater Chem A. $2014 ; 2(21): 7686$.

Imanishi $\mathrm{T}$, Hamano $\mathrm{Y}$, Yoshikawa $\mathrm{H}$, Iwata C. 1-Substituted (S)-3-(p-tolyl)sulphinyl-1,4dihydropyridines: novel NADH model compounds. J Chem Soc Chem Commun. 1988;(7):473.

Khenkin AM, Efremenko I, Weiner L, Martin JML, Neumann R. Photochemical Reduction of Carbon Dioxide Catalyzed by a Ruthenium-Substituted Polyoxometalate. Chem - A Eur J. 2010 Jan 25;16(4):1356-64.

Kobayashi K, Ohtsu H, Nozaki K, Kitagawa S, Tanaka K. Photochemical Properties and Reactivity of a $\mathrm{Ru}$ Compound Containing an NAD/NADHFunctionalized 1,10-Phenanthroline Ligand. Inorg Chem. 2016 Mar 7;55(5):2076-84.

KoizumiTA, Tanaka K. Reversiblehydridegeneration and release from the ligand of $[\mathrm{Ru}(\mathrm{pbn})(\mathrm{bpy}) 2]$ (PF6) 2 driven by a pbn-localized redox reaction. Angew Chemie - Int Ed. 2005;44(36):5891-4.

Li H, Worley KE, Calabrese Barton S. Quantitative Analysis of Bioactive NAD+ Regenerated by NADH Electro-oxidation. ACS Catal. 2012 Dec 7;2(12):2572-6.

Limoges B, Marchal D, Mavré F, Savéant J-M. Electrochemistry of Immobilized Redox Enzymes: Kinetic Characteristics of NADH Oxidation Catalysis at Diaphorase Monolayers Affinity Immobilized on Electrodes. J Am Chem Soc. 2006 Feb;128(6):2084-92.

Ma Y, Jin Z, Peng B, Ding J, Wang N, Zhou M. Investigation of Direct Electrooxidation Behavior of $\mathrm{NADH}$ at a Chemically Modified Glassy Carbon Electrode. J Electrochem Soc. 2015 Feb 24;162(6):H317-20.

Meyers AI, Oppenlaender T. Efficient chirality transfer between a chiral 4-methyl-1,4dihydropyridine and benzoylformic ester. An example of a pure intermolecular self-immolative process. J Am Chem Soc. 1986 Apr;108(8):198996.

Mitrasinovic PM. Sharing analysis of the behavior of electrons in some simple ylides. Chem Phys. 2003 Jan;286(1):1-13.

Molnar SM, Nallas G, Bridgewater JS, Brewer KJ. Photoinitiated Electron Collection in a Mixed-Metal Trimetallic Complex of the Form $\{[($ bpy $) 2 \mathrm{Ru}(\mathrm{dpb})] 2 \operatorname{IrCl} 2\}(\mathrm{PF} 6) 5$ (bpy = 2,2'-Bipyridine and $\mathrm{dpb}=2,3$-Bis (2-pyridyl) benzoquinoxaline). J Am Chem Soc. 1994 Jun;116(12):5206-10.

Nakajima H, Tanaka K. Novel Reversible Metallacyclization in $[\mathrm{Ru}(\mathrm{bpy}) 2$ ( $\eta 1$-napy) $(\mathrm{CO})]$ $2+$ (bpy $=2,2$-bipyridine, napy $=1,8$-naphthyridine $)$ by Intramolecular Attack of Non-Bonded Nitrogen of napy to Carbonyl Carbon. Chem Lett. 1995 Oct;24(10):891-2.

Ohnishi Y, Kagami M, Ohno A. Reduction by a model of $\mathrm{NAD}(\mathrm{P}) \mathrm{H}$. Effect of metal ion and stereochemistry on the reduction of .alpha.-keto esters by 1,4-dihydronicotinamide derivatives. J Am Chem Soc. 1975 Aug;97(16):4766-8. 
Ohno A, Ikeguchi M, Kimura T, Oka S. Reduction by a model of $\mathrm{NAD}(\mathrm{P}) \mathrm{H}$. 25. A chiral model which induces high asymmetry. J Am Chem Soc. 1979 Nov;101(23):7036-40.

Ohno A, Ikeguchi M, Kimura T, Oka S. Asymmetric reduction of methyl benzoylformate with a chiral $\mathrm{NAD}(\mathrm{P}) \mathrm{H}$-model compound. J Chem Soc Chem Commun. 1978;(7):328.

Ohtsu H, Tsuge K, Tanaka K. Remarkable accelerating and decelerating effects of the bases on $\mathrm{CO} 2$ reduction using a ruthenium NADH model complex. J Photochem Photobiol A Chem. 2015 Dec;313:163-7.

Polyansky DE, Cabelli D, Muckerman JT, Fukushima T, Tanaka K, Fujita E. Mechanism of Hydride Donor Generation Using a Ru(II) Complex Containing an NAD + Model Ligand: Pulse and Steady-State Radiolysis Studies. Inorg Chem. 2008 May;47(10):3958-68.

Radoi A, Compagnone D. Recent advances in $\mathrm{NADH}$ electrochemical sensing design. Bioelectrochemistry. 2009 Sep;76(1-2):126-34.

Santhanam KS V., Elving PJ. Electrochemical redox pattern for nicotinamide species in nonaqueous media. J Am Chem Soc. 1973 Aug;95(17):5482-90.

Scipioni R, Pumera M, Boero M, Miyahara Y, Ohno T. Investigation of the Mechanism of Adsorption of $\beta$-Nicotinamide Adenine Dinucleotide on SingleWalled Carbon Nanotubes. J Phys Chem Lett. 2010 Jan $7 ; 1(1): 122-5$.

Seki M, Baba N, Oda J, Inouye Y. High enantioselectivity in reductions with a chiral bis(NADH) model compound. J Am Chem Soc. $1981 \mathrm{Jul} ; 103(15): 4613-5$.

Seki M, Baba N, Oda J, Inouye Y. High enantioselectivity in reductions with a chiral polymethylene-bridged bis(NADH) model compound. J Org Chem. 1983 Apr;48(8):1370-3.

Takeda $\mathrm{H}$, Koike $\mathrm{K}$, Inoue $\mathrm{H}$, Ishitani $\mathrm{O}$. Development of an Efficient Photocatalytic System for CO 2 Reduction Using Rhenium(I) Complexes Based on Mechanistic Studies. J Am Chem Soc. 2008 Feb;130(6):2023-31.

Tannai H, Koizumi T, Wada T, Tanaka K. Electrochemical and Photochemical Behavior of a Ruthenium(II) Complex Bearing Two Redox Sites as a Model for the NAD+/NADH Redox Couple. Angew Chemie Int Ed. 2007 Sep 17;46(37):7112-5.
Tomon T, Koizumi T, Tanaka K. Electrochemical Hydrogenation of $[\mathrm{Ru}($ bpy $) 2($ napy $-\kappa \mathrm{N})(\mathrm{CO})] 2+$ : Inhibition of Reductive RuCO Bond Cleavage by a Ruthenacycle. Angew Chemie Int Ed. 2005 Apr 8;44(15):2229-32.

Vidugiriene J, Leippe D, Sobol M, Vidugiris G, Zhou W, Meisenheimer P, et al. Bioluminescent Cell-Based NAD(P)/NAD(P)H Assays for Rapid Dinucleotide Measurement and Inhibitor Screening. Assay Drug Dev Technol. 2014 Dec;12(9-10):51426.

White H. Evolution of Coenzymes and the Origin of Pyridine Nucleotides. New York: Academic Press; 1982. 4-11 p.

Wouters KL, de Tacconi NR, Konduri R, Lezna RO, MacDonnell FM. Driving Multi-electron Reactions with Photons: Dinuclear Ruthenium Complexes Capable of Stepwise and Concerted Multi-electron Reduction. Photosynth Res. 2006 Jan 19;87(1):4155.

Zhao J, Wang N-X, Wang W-W, Liu Y-H, Li L, Wang G-X, et al. A New Type of NADH Model Compound: Synthesis and Enantioselective Reduction of Benzoylformates to the Corresponding Mandelates. Molecules. 2007 May 11;12(5):97987.

For a review on benzoylformate reduction by NADH mimics see: (a) Eisner U, Kuthan J. Chem Rev. 1972; 72:1-42; (b) Stout DM, Meyers AI. Chem Rev. 1982; 82:223-243; (c) Burgess VA, Davies SG, Skerlj RT. Tetrahedron: Asymmetry. 1991; 2:299-328; (d) Murakami Y, Kikuchi JI, Hisaeda Y, Hayashida O. Chem Rev. 1996; 96:721-758; (e) Wang NX, Zhao J. Chin J Org Chem. 2006; 26:775-782; (f) Xu HJ, Liu YC, Fu Y, Wu YD. Org Lett. 2006; 8:3449-3451.

For a review NADH mimics see: (a) Burgess VA, Davies SG, Skerlj RT. Chem Commun. 1990; 1759-1762; (b) Combret Y, Torché JJ, Binay B, Dupas G, Bourguignon J, Quéguiner G. Chem Lett. 1991; 20:125-128; (c) Combret Y, Duflos J, Dupas G, Bourguignon J, Quéguiner G. Tetrahedron: Asymmetry. 1993; 4:1635-1644; (d) Combret Y, Duflos J, Dupas G, Bourguignon J, Quéguiner G. Tetrahedron. 1993; 49:5237-5246; (e) Bédat J, Levacher V, Dupas G, Quéguiner G, Bourguignon J. Chem Lett. 1996; 25:359-360; (f) Obika S, Nishiyama T, Tatematsu S, Miyashita K, Iwata C, Imanishi T. Tetrahedron. 1997; 53:593-602; (g) Li J, Liu YC, Deng JG. Tetrahedron: Asymmetry. 1999; 10:4343-4347; (h) Stéphane G, Cyril P, Francis M, Georges D, Vincent L. Synlett. 2005; 
3:441-444; (i) Xie K, Liu YC, Cui Y, Wang JG, Fu Y, Mak TCW. Molecules. 2007; 12:415-422.

For a list of preliminary research work on $\mathrm{NAD}+1$ NADH mimics: a) Ohnishi Y, Kagami M, Ohno A. J Am Chem Soc. 1975; 97:4766; b) Ohno A, Ikeguchi M, Kimura T, Oka S. J Am Chem Soc. 1979; 101:7036; c) Baba N, Oda J, Inouge Y. Asymmetric Synth. 1983; 2:91; d) Tahna AG, Jouin P, De Vries JG, Trootswijk CB, Werumeus Buning GH, Waninge JK, Vissher J, Kellogg RM. J Am Chem Soc. 1985; 107:3981; e) Zehani S, Lin J, Gelbard G. Tetrahedron. 1989; 45:733. 